\title{
Prevalence, perception and correlates of low back pain among healthcare workers in tertiary health institutions in Sokoto, Nigeria
}

\author{
Kehinde J. Awosan $^{1 *}$, Semen S. Yikawe ${ }^{2}$, Oche M. Oche ${ }^{1}$ and Muhammad Oboirien ${ }^{3}$ \\ Ghana Med J 2017; 51(4): 164-174 http://dx.doi.org/10.4314/gmj.v51i4.4
}

${ }^{1}$ Department of Community Health, Usmanu Danfodiyo University, Sokoto, Nigeria, ${ }^{2}$ Department of OrthoRhino-Laryngology, Usmanu Danfodiyo University Teaching Hospital, Sokoto, Nigeria, ${ }^{3}$ Department of Surgery, Usmanu Danfodiyo University, Sokoto, Nigeria.

Corresponding author: Kehinde J. Awosan $\quad$ E-mail: awosankj1@gmail.com

Conflict of interest: None declared

\section{SUMMARY}

Background: Low back pain (LBP) is a common cause of disability worldwide. Healthcare workers are particularly prone to it because of the physical and emotional factors associated with their profession.

Objectives: To determine the prevalence, perception and correlates of LBP among healthcare workers in tertiary health institutions in Sokoto, Nigeria.

Methods: A cross-sectional study was conducted among 320 healthcare workers selected by multistage sampling technique from July to September 2016. Anthropometry was done for the participants in addition to questionnaire administration.

Results: The mean age of the study participants was $36.99 \pm 8.23$ years. The lifetime, annual, and point prevalence of LBP among the participants were $56.2 \%, 39.1 \%$ and $17.2 \%$ respectively. Most, $151(83.9 \%)$ of the 180 participants that have ever experienced LBP reported that it commenced after starting work, and they perceived it to be due to standing for long hours $(57.2 \%)$, awkward postures $(22.2 \%)$ and carrying heavy objects/patients at work $(20.6 \%)$. Older age, female sex, longer duration of practice, overweight/obesity, and lifting heavy objects/patients at work were significantly associated with LBP among the participants.

Conclusion: The prevalence of LBP is high among healthcare workers in Sokoto, Nigeria; although it was also associated with older age and female sex, being in practice for 10 years and above, overweight/obesity, and lifting heavy objects/patients at work were the predictors identified. Management of the respective hospitals should prevent workplace exposures to heavy weight/objects by establishing "lift teams" as a temporary measure, and also implement "zero lift programs" in their facilities.

\section{Funding: Nil}

Keywords: Prevalence, perception, correlates, low back pain, healthcare workers.

\section{INTRODUCTION}

Low back pain (LBP) is one of the most common causes of musculoskeletal disorders related to work status and condition. ${ }^{1}$ It is estimated that as much as $80 \%$ of the general population will experience a back problem at some time in their lives. ${ }^{2}$ The incidence of LBP peaks in the third decade of life, and the prevalence increases until the age of 60 to 65 years and then gradually declines. ${ }^{3}$ In the Global Burden of Disease 2010, LBP was listed among the top ten high burden diseases and injuries. ${ }^{4}$ Low back pain has been shown to account for an average number of disability-adjusted life years (DALYs) higher than HIV, road injuries, tuberculosis, lung cancer, chronic obstructive pulmonary disease and preterm birth complications. ${ }^{4}$

Low back pain was estimated to contribute 58.2 million DALYs to the global burden of disease in 1990, ranking it as the 11th leading global contributor to years lost from premature mortality or years lived in ill health. For 2010, low back pain was ranked the sixth leading contributor to overall disease burden, estimated to be 83 million DALYs. ${ }^{5}$ 
The effects of low back pain in terms of quality of life, productivity and workers' absenteeism are enormous. ${ }^{6}$ LBP causes losses in number of work days which cause significant economic burden to the individuals, their families and the society. ${ }^{6}$

Several studies have been carried out in Europe to evaluate the social and economic impact of low back pain. In the United Kingdom, low back pain was identified as the most common cause of disability in young adults, with more than 100 million work days lost per year. ${ }^{4}$ In the United States, an estimated 149 million work days are lost every year because of LBP with total costs estimated to be 100 to 200 billion US dollar a year. $^{7,8}$

Until 10 years ago, LBP was largely thought of as a problem confined to Western countries, however, since that time an increasing amount of research has demonstrated that low back pain is also a major problem in low and middle-income countries. ${ }^{9}$ A systemic review of 27 epidemiological studies across Africa showed that, there is little difference in the prevalence of LBP among African as compared to the developed countries, with prevalence of $28-74 \%{ }^{10}$

Healthcare workers are at risk of having LBP because of the physical and emotional factors associated with their profession. ${ }^{11}$ Healthcare workers often experience low back pain at a rate exceeding that of workers in construction, mining, and manufacturing. ${ }^{12}$ These injuries are due in large part to repeated manual patient handling activities, often involving heavy manual lifting associated with transferring, repositioning patients and working in extremely awkward postures. ${ }^{1}$

Among healthcare personnel, nurses and operating room staff are known to have the highest rate of back pain with an annual prevalence of $40-50 \%$ and a lifetime prevalence of $35-80 \%{ }^{13,14}$ The influence of the perceived cause(s) and severity of disease on the healthseeking behavior of individuals and communities has been demonstrated in several studies across the globe. ${ }^{15,16,17,18}$ The perception and opinions of healthcare workers on any disease condition is very important because the members of the community often look up to them for counseling and treatment of various ailments. Low back pain is a condition that affects a significant proportion of the general population and therefore the perception and opinions of this condition among healthcare workers will invariably affect their healthseeking behavior, compliance with preventive measures, education of their patients on these preventive measures, and invariably the perception of the disease by the general population. ${ }^{7}$ Healthcare workers often believe that low back pain is occupationally related. ${ }^{19,20}$

While it may be true that certain activities in the work place may precipitate or aggravate LBP, not all LBP among healthcare workers is caused by activities in the work place. ${ }^{1}$

These erroneous perceptions may force administrators to post out workers who have LBP or are at risk of such to units where their services may not be needed, thus causing a reduction in the efficiency of the healthcare system. Identifying these perceptions and correcting erroneous ones through sensitization and health education is very important.

There are various risk factors (correlates) that have been associated with LBP. ${ }^{11,21}$ Most authors agree that advancement in age and female gender are associated with higher prevalence of LBP. ${ }^{1,11,12,22}$ There are however conflicting opinions on the effect of psychosocial factors like alcohol consumption, physical exercise and depression on LBP. ${ }^{11,23,24,25}$ These conflicting opinions discourage preventive efforts that should have been directed towards such risk factors. In Nigeria, of serious concern is the very high prevalence of LBP reported in studies conducted both among healthcare workers $(73.53 \%),{ }^{26}$ and other occupational groups including industrial workers $(59.7 \%),{ }^{27}$ farmers $(74.4 \%),{ }^{28}$ professional drivers $(73.5 \%),{ }^{29}$ automotive maintenance mechanics $(76.02 \%),{ }^{30}$ and hairdressers $(76.3 \%))^{31}$ In addition, considering the documented evidence of a past history of LBP as a risk factor for recurrence, ${ }^{32,33}$ the relatively high prevalence of LBP recorded in studies among adolescents in Nigeria (with a lifetime prevalence of 58 to $59 \%$, and point prevalence of 14.7 to $17.0 \%)^{34,35}$ is threatening enough, in view of the high likelihood of the problem tracking into adulthood with dire consequences. These reports indicate very high burden of LBP across the various age and occupational groups in Nigeria. The burden of LBP, particularly among healthcare workers and other "at risk groups" in Sokoto, Nigeria, is largely unknown. Research to estimate the burden and identify the risk factors associated with LBP in our environment is needed to guide policy makers and human resource managers in designing preventive strategies. This study was conducted to assess the prevalence, perception and correlates of low back pain among healthcare workers in tertiary health institutions in Sokoto metropolis. 


\section{METHODS}

\section{Study design and population}

This was a descriptive cross-sectional study conducted among healthcare workers working in the two tertiary health institutions in Sokoto metropolis, the capital of Sokoto state, in Northwestern Nigeria, from July to September 2016. Sokoto state has a population of $3,696,999$ people, based on the 2006 census with an estimated population of 4,802,298 projected for 2015 . $^{36}$ Sokoto metropolis has a total of 86 health facilities (2 tertiary, 5 secondary, and 79 primary health facilities). The two tertiary health facilities in the metropolis include Usmanu Danfodiyo University Teaching Hospital (an 850-bed capacity hospital, which takes care of patients from Sokoto, Kebbi, Zamfara, Katsina, and Niger states), and Sokoto State Specialist Hospital (a 270 bed capacity hospital, which receives referrals from primary and secondary health facilities within and outside Sokoto state).

Those that have worked for at least one year in the respective hospitals and gave their consent to participate were considered eligible for enrolment into the study. Those with history of trauma to the back or surgery performed on the back in the last 6 weeks were excluded. The sample size was estimated at 320 using the using the Fisher's formula for proportion, ${ }^{37}$ a $72.5 \%$ prevalence of low back pain among healthcare workers in a previous study, ${ }^{11}$ a precision of $5 \%$ and an anticipated response rate of $95 \%$.

The number of health workers to be selected in each of the tertiary health institutions was determined by proportionate allocation based on their staff population. The eligible participants were selected by a two-stage sampling technique. At the first stage, 10 of 20 departments, and 6 of 11 departments were selected at Usmanu Danfodiyo University Teaching Hospital and Specialist Hospital respectively by simple random sampling using the ballot option. At the second stage, the number of participants to be enrolled into the study in each of the selected departments was determined by proportionate allocation (based on the staff strength), the health workers in the respective departments were then stratified by cadre and the number of participants to be selected from each cadre was also determined by proportionate allocation. Finally, selection of the required number of health workers from each cadre was done by simple random sampling using the ballot option.

\section{Data collection}

The methods of data collection comprised of questionnaire administration and physical assessment (anthropometry). A standardized semi-structured, selfadministered questionnaire was used to obtain information on study participants' socio-demographic characteristics; and prevalence, perception and correlates of low back pain among them. The various sections of the questionnaire were adapted from the instrument used in previous studies. ${ }^{11,12,21,25,38}$ The questionnaire instrument was pre-tested on 15 healthcare workers in one of the departments not selected for the study; the questions were well understood by the respondents and no modification was necessary.

Anthropometry (weight and height measurement) was done for the participants. Weight was measured with shoes off to the nearest $0.5 \mathrm{~kg}$ using a Seca Optimal scale; it was validated with a standard weight and corrected for zero error. Height was measured without shoes to the nearest $0.5 \mathrm{~cm}$ using a stadiometer. The anthropometric assessment was done at the office of the matron in-charge of the respective wards and clinics.

Six resident doctors assisted in data collection after pretraining on the objectives of the study, selection of study participants and use of survey instruments. Approval for the study was obtained from the Research and Ethics Committee of Usmanu Danfodiyo University Teaching Hospital and Sokoto state Ethical Committee. Permission was obtained from the Management of the two hospitals before the study commenced, and informed written consent was obtained from each prospective study participant before enrolment into the study.

\section{Operational definition of terms}

Body mass index (BMI) was calculated as weight $(\mathrm{kg})$ divided by height ${ }^{2}\left(\mathrm{~m}^{2}\right)$ and used as marker for nutritional status. ${ }^{39}$ Underweight was defined as BMI less than $18.5 \mathrm{~kg} / \mathrm{m}^{2}$, normal weight was defined as BMI of 18.5 to $24.9 \mathrm{~kg} / \mathrm{m}^{2}$, overweight was defined as BMI of 25.0 to $29.9 \mathrm{~kg} / \mathrm{m}^{2}$, while obesity was defined as BMI of $30.0 \mathrm{~kg} / \mathrm{m}^{2}$ and above.

\section{Data analysis}

The questionnaires were manually checked for accuracy and completeness. Data were cleaned, entered into and analyzed using IBM Statistical Package for Social Sciences (SPSS) Version 21. Quantitative variables were summarized using mean and standard deviation while categorical variables were summarized using frequencies and percentages. 
Chi-square test was used for the comparison of proportions and logistic regression analysis was used in determining the variables that predict LBP among the participants. All statistical analysis was set at $5 \%$ level of significance (i.e. $\mathrm{p}<0.05$ ).

\section{RESULTS}

The ages of the 320 participants ranged from 21 to 58 years $($ mean $=36.99 \pm 8.23)$, with a larger proportion $(45.0 \%)$ in the $30-39$ years age group. The participants were predominantly females $(60.6 \%)$. Majority of them were either nurses $(46.6 \%)$ or doctors $(25.6 \%)$, and have been in practice for less than a decade (59.2\%) as shown in Table 1.

Table 1 Socio-demographic characteristics of participants

\begin{tabular}{lc}
\hline Variables & $\begin{array}{l}\text { Frequency } \\
(\%) \\
\end{array}$ \\
n= 320 \\
\hline Age group (in years) & $68(21.3)$ \\
$20-29$ & $144(45.0)$ \\
$30-39$ & $74(23.1)$ \\
$40-49$ & $34(10.6)$ \\
$50-59$ & \\
& \\
Sex & $126(39.4)$ \\
Male & $194(60.6)$ \\
Female & \\
& \\
Cadre & $82(25.6)$ \\
Medical doctor & $149(46.6)$ \\
Nurse & $31(9.7)$ \\
Medical laboratory scientist & $6(1.9)$ \\
Physiotherapist & $7(2.2)$ \\
Pharmacist & $42(13.1)$ \\
Cleaner/Ward attendant & $1(0.3)$ \\
Optometrist & $2(0.6)$ \\
CHEW & \\
Length of practice (in years) & \\
(n = 319) & \\
1 - 9 & \\
$10-19$ & $189(59.2)$ \\
$20-29$ & $69(21.6)$ \\
$30-39$ & $47(14.7)$ \\
& $14(4.4)$ \\
\hline
\end{tabular}

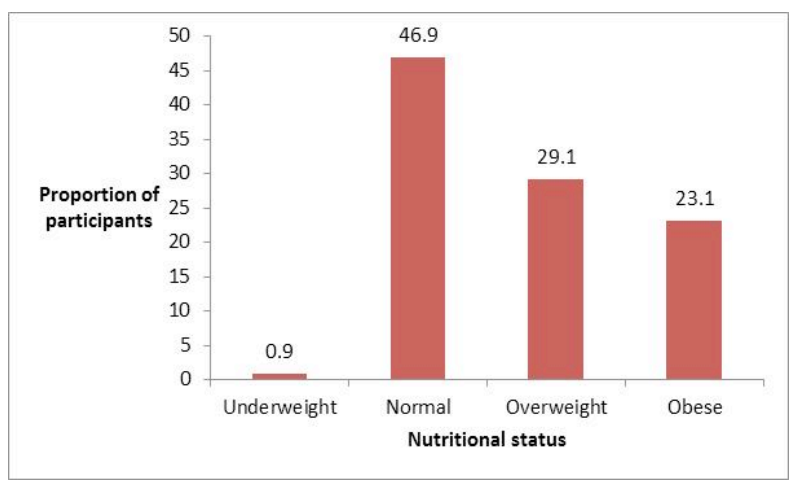

Figure 1 Nutritional status of participants

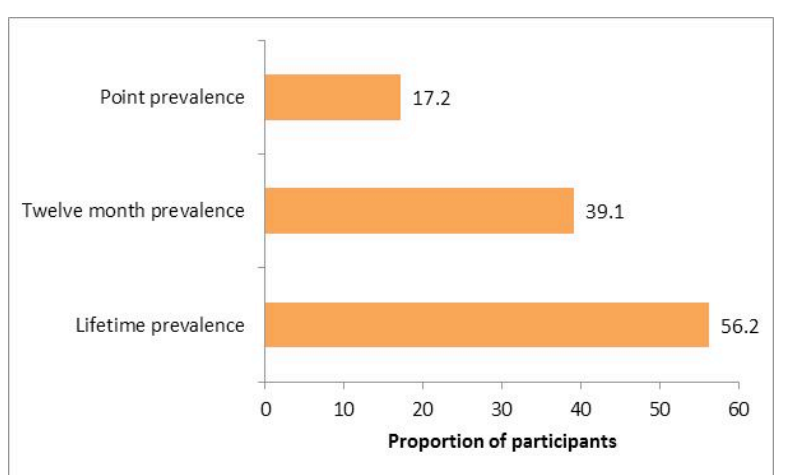

Figure 2 Prevalence of low back pain among participants

\section{Nutritional status of participants}

Three $(0.9 \%)$ of the 320 participants were underweight, $150(46.9 \%)$ had normal weight, 93 (29.0\%) were overweight and 73 (23.1\%) were obese (Figure 1). Most of the participants in the $20-29$ years age group had normal weight, while obesity was significantly more prevalent among the female participants $\left(\chi^{2}=12.623, \mathrm{p}\right.$ $=0.006)$, and those that were aged 50 years and above $\left(\chi^{2}=56.350, \mathrm{p}<0.001\right)$ as shown in Table 2 .

\section{Prevalence of low back pain among participants}

One hundred and eighty (56.2\%) of the 320 participants have ever experienced LBP in their lifetime, 125 (39.1\%) had experienced it in the last 12 months, while $55(17.2 \%)$ had it at the time of the survey (Figure 2).Compared to males, females had significantly higher $(\mathrm{p}<0.05)$ lifetime prevalence (males $40.5 \%$, females $59.8 \%$ ), 12 month prevalence (males 29.4\%, females $43.3 \%$ ) and point prevalence (males $11.9 \%$, females $20.6 \%$ ) of LBP. Whereas the lifetime prevalence of LBP was significantly higher among cleaners/ward attendants $(61.9 \%)$, doctors $(61.0 \%)$ and nurses $(55.3 \%)$ compared with the other cadres, the differences in the 12 month and point prevalence of LBP were insignificant $(p>0.05)$, but they were more prevalent among nurses compared with the other cadres (Table 3 ). 
Perception of low back pain by participants

Most, 151 (83.9\%) of the 180 participants that have ever experienced LBP reported that the pain commenced after starting work. Majority, 97 (53.9\%) considered the pain as mild, $74(41.1 \%)$ considered it as moderate, while $9(5.0 \%)$ considered it as severe. Majority, 103 (57.2\%) attributed the pain to standing for long hours at work, $40(22.2 \%)$ attributed it to bending to work, 37 $(20.6 \%)$ attributed it to carrying patients, while 22 $(12.2 \%)$ attributed it performing repetitive tasks. A substantial proportion of the participants reported that LBP has negatively affected their performance at work (32.2\%), other activities after work $(28.3 \%)$ and the quality of their sleep (15.6\%) as shown in Table 4.

Table 2 Distribution of nutritional status by age and sex of participants

\begin{tabular}{|c|c|c|c|c|}
\hline \multirow{3}{*}{ Variables } & \multicolumn{4}{|c|}{ Nutritional status $\mathrm{n}=\mathbf{3 2 0}$} \\
\hline & Underweight & Normal & Overweight & Obese \\
\hline & Frequency $(\%)$ & Frequency $(\%)$ & Frequency $(\%)$ & Frequency $(\%)$ \\
\hline \multicolumn{5}{|c|}{ Age group (in years) } \\
\hline $20-29$ & $1(1.5)$ & $54(79.4)$ & $8(11.8)$ & $5(7.4)$ \\
\hline $30-39$ & $2(1.4)$ & $65(45.1)$ & $49(34.0)$ & $28(19.4)$ \\
\hline $40-49$ & $0(0)$ & $25(33.8)$ & $25(33.8)$ & $24(32.4)$ \\
\hline \multirow[t]{2}{*}{50 and above } & $0(0)$ & $6(17.6)$ & $11(32.4)$ & $17(50.0)$ \\
\hline & \multicolumn{4}{|c|}{$\chi^{2}=56.350, p<0.001$} \\
\hline \multicolumn{5}{|l|}{ Sex } \\
\hline Male & $1(0.5)$ & $80(41.2)$ & $56(28.9)$ & $57(29.4)$ \\
\hline \multirow[t]{2}{*}{ Female } & $2(1.6)$ & $70(55.6)$ & $37(29.4)$ & $17(13.5)$ \\
\hline & \multicolumn{4}{|c|}{$\chi^{2}=12.623, p=0.006$} \\
\hline
\end{tabular}

Table 3 Distribution of prevalence of low back pain by sex and cadre of participants

\begin{tabular}{lccc}
\hline \multirow{2}{*}{ Variables } & \multicolumn{2}{c}{ Prevalence of low back pain } & \\
\cline { 2 - 4 } & $\begin{array}{l}\text { Lifetime } \\
\text { Frequency (\%) }\end{array}$ & $\begin{array}{l}\text { 12 month } \\
\text { Frequency (\%) }\end{array}$ & $\begin{array}{l}\text { Point } \\
\text { Frequency (\%) }\end{array}$ \\
\hline $\begin{array}{l}\text { Sex } \\
\text { Male }(\mathrm{n}=126)\end{array}$ & $50(40.5)$ & $37(29.4)$ & $15(11.9)$ \\
Female $(\mathrm{n}=194)$ & $116(59.8)$ & $84(43.3)$ & $40(20.6)$ \\
& $\chi^{2}=11.42, \mathrm{p}=0.001$ & $\chi^{2}=6.307, \mathrm{p}=0.012$ & $\chi^{2}=4.075, \mathrm{p}=0.044$ \\
Cadre & & & \\
Medical doctor $(\mathrm{n}=82)$ & $50(61.0)$ & $34(41.5)$ & $13(15.9)$ \\
Nurse $(\mathrm{n}=141)$ & $78(55.3)$ & $61(43.3)$ & $33(23.4)$ \\
Medical laboratory scientist & $8(25.8)$ & $6(19.4)$ & $4(12.9)$ \\
(n=31) & $2(33.3)$ & $2(33.3)$ & $0(0)$ \\
Physiotherapist $(\mathrm{n}=6)$ & $1(14.3)$ & $1(14.3)$ & $0(0)$ \\
Pharmacist $(\mathrm{n}=7)$ & $26(61.9)$ & $17(40.5)$ & $5(11.9)$ \\
Cleaner/Ward attendant & & & $0(0)$ \\
( $\mathrm{n}=42)$ & $0(0)$ & $0(0)$ & $0(0)$ \\
Optometrist $(\mathrm{n}=1)$ & $0(0)$ & $0(0)$ & $\chi^{2}=10.135, \mathrm{p}=0.256$ \\
CHEW (n=2) & $\chi^{2}=23.86, \mathrm{p}=0.002$ & $\chi^{2}=15.251, \mathrm{p}=0.054$ \\
& & & \\
\hline
\end{tabular}




\section{Original Article}

Table 4 Perception of low back pain by participants

\begin{tabular}{lc} 
Variables & $\begin{array}{l}\text { Frequency } \\
(\%) \\
\text { n }=\mathbf{1 8 0}\end{array}$ \\
\hline Onset of LBP & $29(16.1)$ \\
Before starting work & $151(83.9)$ \\
After starting work & \\
& \\
Perceived intensity of LBP & $97(53.9)$ \\
Mild & $74(41.1)$ \\
Moderate & $9(5.0)$ \\
Severe & \\
& \\
Perceived cause of LBP & $103(57.2)$ \\
Standing for long hours & $37(20.6)$ \\
Transferring/carrying patients & $7(3.9)$ \\
Lifting heavy objects & $22(12.2)$ \\
Performing repetitive tasks & $3(1.7)$ \\
Falls at work & $3(1.7)$ \\
Working in awkward positions & $40(22.2)$ \\
Bending to work & $2(1.0)$ \\
Sitting for long hours & $3(1.7)$ \\
Pregnancy &
\end{tabular}

\section{Correlates of low back pain among participants}

The prevalence of LBP increased progressively and significantly across the age groups among the participants. The prevalence of LBP among the participants in their $20 \mathrm{~s}, 30 \mathrm{~s}, 40 \mathrm{~s}$ and $50 \mathrm{~s}$ were $31.0 \%$, $50.0 \%, 66.0 \%$ and $73.5 \%$ respectively $\left(\chi^{2}=24.69, \mathrm{p}<\right.$ $0.001)$. LBP was also significantly more prevalent $(\mathrm{p}<$ 0.05 ) among females (59.8\%) than males (40.5); likewise, cleaners/ward attendants $(61.9 \%)$, medical doctors $(61.0 \%)$ and nurses $(55.3 \%)$ compared with the other cadres.

The prevalence of LBP rose progressively and significantly from $40.7 \%$ among the participants that have practiced for less than a decade to $78.6 \%$ among those that have practices for about 3 decades $\left(\chi^{2}=\right.$ $24.636, p<0.001)$. It was also significantly twice as prevalent among overweight and obese participants (69.5\%) compared with those with underweight and normal weight $(33.3 \%)$.

Although, a higher proportion of participants that routinely spend $>8$ hours at work $(61.8 \%)$ reported LBP compared with those that routinely spend $\leq 8$ hours $(49.2 \%)$, the difference was not significant $\left(\chi^{2}=24.636\right.$, $p<0.001)$. LBP was significantly more prevalent among participants that lift heavy objects/patients at work (66.7\%) compared with those who do not (39.4\%), $\chi^{2}=23.72, p<0.001$ (Table 5).

In logistic regression model, length of practice, nutritional status and lifting heavy objects/patients at work were the predictors of LBP. Participants that have worked for 10 years and above were almost twice more likely to have LBP compared with those that have worked for less than 10 years. (Odds Ratio $=1.907$, $95 \% \mathrm{CI}=1.052-3.457, \mathrm{p}=0.033$ ). Overweight/obese participants were almost 4 times more likely to have LBP compared to those with underweight/normal weight (Odds Ratio $=3.908,95 \% \mathrm{CI}=2.353-6.490, \mathrm{p}$ $<0.001)$. Participants that lift heavy objects/patients at work were almost 3 times more likely to have LBP compared with those who do not (Odds Ratio $=2.551$, $95 \% \mathrm{CI}=1.537-4.236, \mathrm{p}<0.001)$ as shown in Table 6.

\section{DISCUSSION}

The mean age of $36.99 \pm 8.23$ and the female predominance among the participants in this study agree with the findings in a study among healthcare workers in South - South Nigeria that reported a mean age of $36.59 \pm 8.6$ years with a male: female ratio of 2:3. ${ }^{12}$ Cunningham et $\mathrm{al},{ }^{[1]}$ working on LBP among Irish Healthcare workers also observed a mean age of 34 years, with females accounting for $71 \%$ of study participants. Abebe et $\mathrm{al}^{25}$ however had a male preponderance in their study, with $52.1 \%$ of the study population being males, and $47.9 \%$ being females, but similar to the finding in this study, nurses constituted the majority.

The $56.2 \%$ lifetime prevalence of LBP observed in this study falls far below the $73.53 \%$ reported in a study among nurses in a hospital in Northern Nigeria, ${ }^{26}$ and $78.1 \%$ reported in another study by Hinmikaiye and Bamishaiye. $^{22}$ Both studies were conducted among nurses alone, who have been observed to have higher prevalence of LBP than other medical staff. ${ }^{40}$ This might have accounted for the higher prevalence of LBP in these studies. The presence of other health professionals with relatively lower prevalence of LBP in this study may have accounted for the lower prevalence observed. Other studies that included other healthcare professionals have observed lower prevalence of LBP among healthcare workers. 
Table 5 Correlates of LBP among participants

\begin{tabular}{|c|c|c|c|}
\hline \multirow[b]{2}{*}{ Variables } & \multicolumn{2}{|c|}{ Presence of LBP $(n=320)$} & \multirow[b]{2}{*}{$\begin{array}{l}\text { Test of } \\
\text { Significance }\end{array}$} \\
\hline & $\begin{array}{l}\text { Yes } \\
\text { Frequency (\%) }\end{array}$ & $\begin{array}{l}\text { No } \\
\text { Frequency (\%) } \\
\end{array}$ & \\
\hline \multicolumn{4}{|l|}{ Age group (in years) } \\
\hline $20-29$ & $21(31.0)$ & $47(69.0)$ & \multirow{4}{*}{$\begin{array}{l}\chi^{2}=24.69 \\
p<0.001\end{array}$} \\
\hline $30-39$ & $72(50.0)$ & $72(50.0)$ & \\
\hline $40-49$ & $49(66.0)$ & $25(34.0)$ & \\
\hline $50-59$ & $25(73.5)$ & $9(26.5)$ & \\
\hline \multicolumn{4}{|l|}{ Sex } \\
\hline Male & $50(40.5)$ & $78(40.2)$ & \multirow{2}{*}{$\begin{array}{l}\chi^{2}=11.424, \\
p=0.001\end{array}$} \\
\hline Female & $116(59.8)$ & $75(59.5)$ & \\
\hline \multicolumn{4}{|l|}{ Cadre } \\
\hline Medical doctor & $50(61.0)$ & $82(25.6)$ & \multirow{8}{*}{$\begin{array}{l}\chi^{2}=23.857 \\
\mathrm{p}=0.002\end{array}$} \\
\hline Nurse & $78(55.3)$ & $149(46.6)$ & \\
\hline Medical laboratory scientist & $8(25.8)$ & $31(9.7)$ & \\
\hline Physiotherapist & $2(33.3)$ & $6(1.9)$ & \\
\hline Pharmacist & $1(14.3)$ & $7(2.2)$ & \\
\hline Cleaner/Ward attendant & $26(61.9)$ & $16(38.1)$ & \\
\hline Optometrist & $0(0)$ & $1(100)$ & \\
\hline CHEW & $0(0)$ & $2(100)$ & \\
\hline \multicolumn{4}{|l|}{ Length of practice } \\
\hline $1-9$ & $77(40.7)$ & $112(59.3)$ & \multirow{4}{*}{$\begin{array}{l}\chi^{2}=24.636, \\
p<0.001\end{array}$} \\
\hline $10-19$ & $45(65.2)$ & $24(34.8)$ & \\
\hline $20-29$ & $33(70.2)$ & $14(29.8)$ & \\
\hline $30-39$ & $11(78.6)$ & $3(21.4)$ & \\
\hline \multicolumn{4}{|l|}{ Nutritional status } \\
\hline Underweight and normal & $51(33.3)$ & $102(66.7)$ & \multirow{2}{*}{$\begin{array}{l}\chi^{2}=41.767 \\
p<0.001\end{array}$} \\
\hline Overweight and obese & $116(69.5)$ & $51(30.5)$ & \\
\hline \multicolumn{4}{|l|}{ Hours spent at work } \\
\hline 8 and below & $120(49.2)$ & $124(50.8)$ & \multirow{2}{*}{$\begin{array}{l}\chi^{2}=3.723 \\
p=0.054\end{array}$} \\
\hline More than 8 & $47(61.8)$ & $29(38.2)$ & \\
\hline \multicolumn{4}{|l|}{ Lifting heavy objects at work } \\
\hline Yes & $100(66.7)$ & $50(33.3)$ & \multirow{2}{*}{$\begin{array}{l}\chi^{2}=23.72 \\
p<0.001\end{array}$} \\
\hline No & $67(39.4)$ & $103(60.6)$ & \\
\hline
\end{tabular}

Table 6 Predictors of LBP among participants

\begin{tabular}{|c|c|c|c|c|}
\hline \multirow[t]{2}{*}{ Variables } & \multirow{2}{*}{$\begin{array}{l}\text { Odds } \\
\text { Ratio }\end{array}$} & \multicolumn{2}{|c|}{ 95\% Confidence Interval } & \multirow[t]{2}{*}{ p value } \\
\hline & & Lower & Upper & \\
\hline Age (below 40 versus 40 years and above) & 0.841 & 0.314 & 2.255 & 0.731 \\
\hline Sex (females versus males) & 0.533 & 0.318 & 0.893 & 0.017 \\
\hline Length of practice (below 10 years versus 10 years and above) & 1.907 & 1.052 & 3.457 & 0.033 \\
\hline $\begin{array}{l}\text { Nutritional status (underweight and normal weight versus overweight } \\
\text { and obese) }\end{array}$ & 3.908 & 2.353 & 6.490 & $<0.001$ \\
\hline Hours spent at work ( 8 and below versus more than 8 ) & 2.532 & 0.781 & 8.204 & 0.121 \\
\hline Lifting heavy objects at work (yes versus no) & 2.551 & 1.537 & 4.236 & $<0.001$ \\
\hline
\end{tabular}


In the study that was conducted among Irish healthcare workers (which was made up of doctors, nurses, general support, administrative, and allied health workers), the lifetime prevalence of LBP was found to be $46 \%$, with an annual prevalence of $30 \%$, and a point prevalence of $15.5 \%{ }^{1}$ Omokhodion et $a,^{38}$ observed a 12-month prevalence of $46 \%$ among healthcare workers working in a rural hospital in Southwest Nigeria, while Johnson and Edward ${ }^{12}$ observed a 12 -month prevalence of $28 \%$.

The findings on the perception of healthcare workers on LBP in this study are in agreement with the study conducted by Omokhodion et al, ${ }^{38}$ among healthcare workers. In their study, $73 \%$ of the respondents believed that the LBP they had was work related. They believed that activities at the work place such as heavy physical work, poor posture and prolonged sitting or standing were responsible for their LBP. In a study conducted by Shah and Dave ${ }^{41}$ among medical doctors in Surat, India, $64.44 \%$ of the doctors agreed that the LBP they had was work related, with $73.33 \%$ of them having LBP only after starting work. They also agreed that prolonged standing, prolonged sitting, and poor/awkward position contributed to the LBP they had. Transferring and lifting patients were the work place activities commonly attributed as a cause of LBP in the study conducted by Hinmikaiye and Bamishaiye. ${ }^{22}$ The study was conducted among theatre nurses who were regularly involved in carrying patients in and out of theatre suites, and it is not surprising that they attributed an activity they carry out the most as a possible cause of their LBP.

Similar findings on the intensity of LBP among respondents in this study was reported in South western Nigeria, with $68 \%$ of respondents describing their pain as mild, $20 \%$ describing their pain as moderate, while $12 \%$ described their pain as severe. ${ }^{38}$ In a crosssectional survey of LBP among 1600 healthcare workers in 6 Turkish hospitals in 4 cities, including nurses, doctors, physical therapist, technicians, secretaries and hospital aides, $63 \%$ of respondents described their pain as moderate, $23.1 \%$ said the pain was severe, while $11.1 \%$ described their pain as mild. ${ }^{36}$ In the study conducted by Johnson and Edward, 42.8\% of the respondents reported that LBP affected their sleep. ${ }^{12}$ Several studies have also reported high prevalence of sleep disturbance among patients with LBP and the sleep disturbance was found to be dependent on the intensity of pain. ${ }^{42,43}$ In another study by Terzi and Altin ${ }^{44}$ chronic fatigue syndrome was found to be statistically significantly more prevalent among study participants with LBP. Pain is a subjective sensation, as different people respond to pain in different ways.
From these studies it can be seen that LBP affects the quality of life of sufferers, as pain alone can reduce their output at work and affect their social life.

Various factors (individual, workplace and psychosocial) have been shown to be associated with occurrence of LBP. Older age was observed to be associated with higher prevalence of low back pain in this study. Individuals whose ages were between 20 29 years had $31 \%$ prevalence of low back pain and this was observed to increase to $73.5 \%$ prevalence for those that were aged between $50-59$ years. In the study conducted by Cunningham et al, ${ }^{1}$ multivariate analysis showed older age as an independent risk factor for LBP. Johnson and Edward ${ }^{12}$ also observed a higher prevalence of LBP $(38.9 \%)$ among respondents that were aged above 35 years against a prevalence of $25 \%$ in those below 35 years.

In this study, longer duration of work was associated with higher prevalence of LBP. This finding was corroborated by the study conducted by Hinmikaiye and Bamishaiye $^{22}$ who observed that respondents that have worked for above 8 years had $47.37 \%$ prevalence of LBP, while those that have worked for below 2 years had $7.02 \%$ prevalence of LBP. Abebe et al, ${ }^{25}$ also observed that healthcare workers that have worked for greater than 12 years had a higher prevalence of LBP than those that have worked for less than 12 years.

Obesity has been shown to be a risk factor for LBP, and this can be explained by the fact that increase in weight puts strain on the weight bearing spinal elements. ${ }^{25}$ This study showed an association between overweight/obesity and higher prevalence of LBP among the respondents. Johnson and Edward also observed that respondents with BMI of 25 and above had significantly higher prevalence of LBP compared with those with BMI below $25^{12}$

Work duration of more than 10 years, female sex and lifting heavy objects were found to be predictors of LBP among the respondents in this study. Although older age was associated with LBP in this study, it was not found to be a predictor of the condition. These findings are in concordance with the findings in a study among Irish healthcare workers in which whereas sex was found to be a predictor of LBP (OR 2.72, 95\% CI $\mathrm{p}=0.001)$, older age was not a predictor. ${ }^{1}$ Similar to the findings in this study, several studies had identified duration of work, female sex and lifting heavy objects as major risk factors for LBP among health care workers. ${ }^{4,46}$ 
The high prevalence of LBP among the participants in this study despite knowing lifting heavy objects to be a risk factor, and the same eventually being a major predictor of LBP among them corroborates the submission of experts that training in proper body mechanics does not prevent back injury; this probably informed the shift in focus to innovative injury prevention programs, including the use of engineering controls as well as the "lift team" method. The "lift team' method was devised to remove nursing personnel from the daily task of moving patients. This type of intervention assumes that lifting is a specialized skill to be performed only by expert professional patient movers who have been trained in the latest lifting device techniques. ${ }^{13}$ Lifting loads over $25 \mathrm{~kg}$ and lifting at a frequency of over 25 lifts per day have been estimated to increase the annual incidence of LBP by 4.32 and $3.50 \%$ respectively. ${ }^{47}$

Studies on the use of mechanical patient lift equipment by either nursing staff or lift team have proven repeatedly that most nursing staff back injury is preventable, leading to substantial savings to employers in medical and compensation costs. ${ }^{48} \mathrm{~A}$ study that assessed the effect of the zero lift programs (defined as replacing manual lifting, transferring and repositioning of patients with mechanical lifting or use of other patient assist devices) in small rural hospitals in Washington state, USA, reported a $43 \%$ decline in patient handling injury claims in the participating hospitals between year 2000 and 2004, while the time lost frequency rate decreased by $50 \%{ }^{49}$

In cognizance of the enormous burden of LBP, its adverse but largely preventable effects on the quality of life and productivity of healthcare workers, and the apathy of the management of health facilities in providing the required safe work environment for their staff, laws have been enacted making it mandatory for hospitals and nursing homes to implement safe patient handling and movement programs in many developed countries such as USA, Australia and UK. ${ }^{48}$ Lofty as this bold step seems, in many resource poor countries (like Nigeria),even though achieving this feat could remain a dream for a long time to come, the fact remains that, with the high burden of LBP among healthcare workers in Nigeria, the need to intervene urgently is indisputable.

\section{CONCLUSION}

The prevalence of LBP is high among healthcare workers in Sokoto, Nigeria; although it was also associated with older age and female sex, being in practice for 10 years and above, overweight/obesity, and lifting heavy objects/patients at work were the predictors identified. Healthcare workers should maintain normal weight and normal postures at work, while the management of the respective hospitals should prevent workplace exposures to heavy weight/objects by establishing "lift teams" as a temporary measure, and also implement "zero lift programs" in their facilities as soon as possible.

\section{ACKNOWLEDGEMENTS}

The authors appreciate the Management of Usmanu Danfodiyo University Teaching Hospital, Sokoto, and Specialist Hospital, Sokoto, the Heads of the various departments used for the study, and all the healthcare workers that participated in the study for their cooperation.

\section{REFERENCES}

1. Cunningham C, Flynn T, Blake C. Low back pain and occupation among Irish health workers. Occup Med 2006; 56(7): 23 - 28.

2. Mafuyai MY, Babangida BG, Mador ES, Bakwa DD, Jabil YY (2014). The increasing cases of lower back pain in developed Nations: a reciprocal effect of development. AJIS 2014; 3(5): 23 - 28.

3. Golob A, Wipf J. Low Back Pain. Med Clin North Am 2014; 98(3), 405-428.

4. Vos T, Flaxman A, Naghavi M, Lozano R, Michaud C, Ezzati $M$ et al. Years lived with disability (YLDs) for 1160 sequelae of 289 diseases and injuries 1990-2010: a systematic analysis for the Global Burden of Disease Study 2010. Lancet 2012; 380(9859): 2163-2196. Available at http://dx.doi.org/10.1016/s0140-6736.

5. Murray C, Vos T, Lozano R, Naghavi M, Flaxman A, Michaud C et al. Disability-adjusted life years (DALYs) for 291 diseases and injuries in 21 regions, 1990-2010: a systematic analysis for the Global Burden of Disease Study 2010. Lancet 2012; 30: 2197-223.

6. Lidgren L. The bone and joint decade 2000-2010. Bulletin of the World Health Organization 2003; 81(9):629. Available at: http://www.who.int/bulletin/volumes/81/9/editorial.

7. CDC. Preventing back injuries in health care settings. Atlanta, USA: Centers for Disease Control and Prevention 2008. Available at: http//: blogs.cdc.gov/niosh - science blog/2008/09/22/lifting.

8. Ansari MA, Subedi K, Panta OB, Suwal S. MRI pattern of lumbosacral degeneration in Tribhuvan University Teaching Hospital, Nepal. JIOM 2015; 38(2): $51-55$. 
9. Jin K, Sorock GS, Courtney TK. Prevalence of low back pain in three occupational groups in Shanghai, People's Republic of China. J Safety Res 2004; 35(1):23-8.

10. Louw Q, Morris L, and Grimmer-Somers K. The Prevalence of low back pain in Africa: a systematic review. BMC Musculoskelet Disord 2007;8(1):105.

11. Wong TS, Teo N, Kyaw MO. Prevalence and risk factors associated with low back pain among healthcare providers in a district hospital. Malays Orthop J 2010; 4(2): 23 - 28.

12. Johnson OE, Edward E. Prevalence and risk factors of low back pain among workers in a health facility in South-South Nigeria. BJMMR 2016; 11(8): 1-8.

13. Edlich RF, Winters KL, Hudson MA, Britt LD, Long WB. Prevention of disabling back injuries in nurses by the use of mechanical lift systems. J Long Term Eff Med Implants 2004; 14(6): 521-33.

14. Homaid MB, Abdelmoehg D, Alshareef W, Alghamdi A, Alhozali F, Hafiz W et al. Prevalence and risk factors of low back pain among operating room staff at a tertiary care centre, Makkah, Saudi Arabia: a cross sectional study. Ann Occup Environ Med 2016; 28:1.

15. Abubakar A, Baar AV, Fisher R, Bomu G, Gona JK, Newton CR. Socio-cultural determinants of health-seeking behavior on the Kenyan coast: a qualitative study. PLoS One 2013; 8(11): e71998.

16. Hasahya OT, Berggren V, Sematimba D, Nabirye RC, Kumakech E. Beliefs, perception and healthseeking behavior in relation to cervical cancer: a qualitative study among women in Uganda following completion of an HPV vaccination campaign. Global Health Action 2016; 9. Doi: 10.3402/gha.v9.29336.

17. Peppa M, Edmunds WJ, Funk S. Disease severity determines health-seeking behavior among individuals with influenza-like illness in an internet-based cohort. BMC Infect Dis 2017; 17: 238. Doi; 10.1186/s12879-017-2337-5.

18. Laar AS, Laar AK, Dalinjong PA. Community perception of malaria and its influence on healthseeking behavior in rural Ghana; a descriptive study. Malaria World J 2013; 4(1): 1-6.

19. Shams VS, Sarkhosh KR, Rajaei GR, Adimi I. Evaluation of prevalence of low back pain among residents of Tabriz University of Medical Sciences in relation to their position in work. Turk $J$ Emerg Med 2016; 14(3): 125-9.

20. Minematsu A. Understanding and preventing low back pain in care workers. J Jpn Phys Ther Assoc 2007; 10(1): 27-31.

21. Tinubu B, Mbada C, Oyeyemi A, Fabunmi A. Work-Related Musculoskeletal Disorders among Nurses in Ibadan, South-west Nigeria: a cross- sectional survey. BMC Musculoskeletal Disorders 2010. Available at: http://www.biomedcentral.com/.

22. Hinmikaiye CD, Bamishaiye EI. The incidence of low back pain among theatre nurses: a case study of University of Ilorin and Obafemi Awolowo University Teaching Hospital. Nursing 2012; 2(3): 23- 28.

23. Leboeuf-Yde C. Body weight and low back pain: a systematic literature review of 56 journal articles reporting on 65 epidemiologic studies. Spine 2000; 25(2): 226.

24. Shiri R, Karppinen J, Leino-Arjas P, Solovieva S, Viikari-Juntura E. The association between smoking and low back pain: a meta-analysis. Am J Med 2010; 123(1): 87.e735.doi:10.1016/j.amjmed.2009.05.028.

25. Abebe AD, Gebrehiwot EM, Lema S, Abebe TW. Prevalence of low back pain and associated risk factors among Adama Hospital Medical College Staff, Ethiopia. EJPM 2015; 3(6): 188 - 192.

26. Sikiru L, Hanifa S. Prevalence and risk factors of low back pain among nurses in a typical Nigerian hospital. Afr Health Sciences 2010; 10(1): 26-30.

27. Sanya AO, Ogwumike OO. Low back pain prevalence amongst industrial workers in the private sector in Oyo state, Nigeria. Afr J Med Med Sci 2005; 34(3): 245-9.

28. Tella BA, Akinbo SR, Asafa SA, Gbiri CA. Prevalence and impacts of low back pain among peasant farmers in South-west Nigeria. Int J Occup Med 2013; 26(4): 621-7.

29. Rufai AA, Saidu IA, Ahmad RY, Elmi OS, Aliyu SU Jajere AM et al. Prevalence and risk factors for low back pain among professional drivers in Kano, Nigeria. Arch Environ Occup Health 2015; 70(5): 251-5.

30. Abaraogu UO, Ezema CI, Igwe SE, Egwuonwu AV, Okafor UC. Work-related back discomfort and associated factors among automotive maintenance mechanics in Eastern Nigeria: a cross sectional study. Work 2016; 53(4): 813-23.

31. Aweto HA, Tella BA, Johnson OY. Prevalence of work-related musculo-skeletal disorders among hairdressers. Int J Occup Med Environ Health 2015; 28(3): 545-55.

32. Bejia I, Younes M, Jamila HB, Khalfallah T, Ben Salem K, Touzi $M$ et al. Prevalence and factors associated to low back pain among hospital staff. Joint bone Spine 2005; 72(3): 254-9.

33. Ghoussoub K, El Asmar A, Kreichati O, Wakim S, Bakhache M, Baz $\mathrm{M}$ et al. Prevalence and risk factors associated with low back pain among hospital staff in a university hospital in Lebanon. Ann Phys Rehabil Med 2016; 59Se146. 
34. Adegoke BO, Odole AC, Adeyinka AA. Low back pain among secondary school students in Ibadan, Nigeria. Afr Health Sci 2015; 15(2): 429-37.

35. Ayanniyi O, Mbada CE, Muolokwu CA. prevalence and profile of back pain in Nigeria adolescents. Med Princ Pract 2011; 20(4): 368-73.

36. NPC and ICF Macro. Nigeria demographic and health survey 2008. Abuja, Nigeria. National Population Commission and ICF Macro; 2009.

37. Ibrahim T. Sample size estimation. In; Research methodology and dissertation writing for Health and Allied Health professionals. Abuja: Cress Global Link Ltd 2009.

38. Omokhodion FO, Umar US, Ogunnowo BE. Prevalence of low back pain among staff in a rural hospital in Nigeria. Occup Med 2000; 50: 107 110.

39. Tsigos C, Hainer V, Basdevant A, Finer N, Friend M, Maths-Vliegen E, et al. Management of Obesity in Adults: European Clinical Practice Guidelines. Obesity Facts 2008; 1(2): 106-116.

40. Karahan A, Kav S, Abbasoglu A, Dogan N. Low back pain: prevalence and associated risk factors among hospital staff. $J$ Adv Nurs 2009; 65(3): 516524.

41. Shah S, Dave B. Prevalence of low back pain and its associated risk factors among doctors in Surat. Int J Health Sci Res 2012; 2(1): 91-102.

42. Alsaadi SM, McAuley JH, Hush JM, Maher CG. Prevalence of sleep disturbance in patients with low back pain. Eur Spine J 2011; 20(5): 737-43.
43. Kelly GA, Blake C, Power CK, O'Keiffi D, Fullen BM. The association between chronic low back pain and sleep: a systematic review. Clin J Pain 2011; 27(2): 169-81.

44. Terzi R, Altin F. The prevalence of low back pain in hospital staff and its relationship with chronic fatigue syndrome and occupational factors. Agri 2015; 27(3): 149-54.

45. Landry MD, Raman SR, Sulway C, Golightly YM, Hamdan E. Prevalence and risk factors associated with low back pain among healthcare workers in a Kuwait hospital. Spine 2008; 33(5): 539-45.

46. Quedraogo DD, Quedraogo V, Quedraogo LT, Kinda M, Tieno H, Zoungrana EI et al. Prevalence and factors associated with low back pain among hospital staff in Quagodogou (Burkina Faso). Med Trop 2010; 70(3): 277-80.

47. Coenen P, Gouttebarge V, van der Burght AS, van Dieen JH, Frings DMH, van der Beek AJ et al. The effect of lifting during work on low back pain: a health impact assessment based on meta-analysis. Occup Environ Med 2014; 71(12): 871-7.

48. Hudson MA. Texas passes first law for safe patient handling in America: landmark legislation protects healthcare workers and patients from injury related to manual patient lifting. J Long Term Eff Med Implants 2005; 15(5): 559-66.

$\checkmark \sharp$ Charney W, Simmons B, Lary M, Metz S. Zero lift programs in small rural hospitals in Washington state: reducing back injuries among health care workers. AAOHN J 2006; 54(8): 355-8. 